Research Article

\title{
Breaking and Instability Movement Characteristics of High-Position Double-Layer Hard Thick Strata due to Longwall Mining
}

\author{
Pu Wang $\mathbb{D}^{1},{ }^{1}$ Jinquan Jiang $\mathbb{D}^{1},{ }^{1}$ and Bin $X \mathbf{u}^{2}$ \\ ${ }^{1}$ College of Resources, Shandong University of Science and Technology, Tai'an 271019, China \\ ${ }^{2}$ Mining Engineering Research Institute, Shandong University of Science and Technology, Tai'an 271019, China
}

Correspondence should be addressed to Jinquan Jiang; jjqsd@163.com

Received 25 September 2020; Revised 27 October 2020; Accepted 9 December 2020; Published 24 December 2020

Academic Editor: Wenfeng Li

Copyright (c) $2020 \mathrm{Pu}$ Wang et al. This is an open access article distributed under the Creative Commons Attribution License, which permits unrestricted use, distribution, and reproduction in any medium, provided the original work is properly cited.

With multilayer hard roof occurring above the mining area, the strata behaviors will be significantly affected by their special characteristics and interaction. In this paper, relying on the mining background of panel 1061 of a coalmine, the breaking instability of double-layer hard thick strata (DLHTS) and the precursory information of disasters are studied by using theoretical analysis, numerical simulation, and physical simulation. Results show that the DLHTS have bearing, blocking, and controlling effects. Prior to DLHTS breaking, the horizontal development of stress concentration zone and plastic zone can be controlled, and the overburden movement is gentle, while during the breaking process, the stress drops abruptly, the plastic zone expands longitudinally rapidly, the overburden moves notably, and the energy release is sharp, which is likely to directly cause strong dynamic pressure. Moreover, the DLHTS can interact with and influence each other; that is to say, the breaking of lower magmatic rock (LMR) can provide sufficient space for that of upper magmatic rock (UMR), while the UMR breaking can promote the LMR periodic breaking in turn and cause its secondary instability, thereby easily causing complex or composite dynamic disasters' formation. Hence, compared with single hard thick stratum occurrence, the strata behaviors affected by DLHTS breaking and instability are normal and more intense. Study results can provide a scientific basis for the prevention and control of dynamic disaster with hard thick stratum occurrence and important guidance value for promoting safe and efficient production of coalmines.

\section{Introduction}

According to data statistics, about $30 \%$ of the Chinese coalmines are covered with a hard thick roof, such as hard thick magmatic rock in Yangliu coalmine in Huaibei, thick red sandstone in Baodian coalmine in Jining, and huge thick conglomerate in Yima coalmine in Henan [1-3]. The highposition hard thick roof has the characteristics of high strength and large distance from the coal seam, which easily induced the overburden movement and structure, and strata behaviors' manifestation under mining disturbance has obvious variation. For instance, the large bed separation is prone to form beneath the hard thick roof, the roof will lose its stability once it is broken, thereby inducing disasters such as roof dynamic loading, hurricane, and rock bursts [4-7].
Moreover, if under the condition of coal seam group mining, it is easy to communicate the abandoned goaf at the upper part, so that the harmful gas, ponding, and hidden fire area can be connected to the working face, which can form potential safety hazards such as gas burst, water permeability, and fire [8-10].

Considerable studies have been conducted to study the breaking law and dynamic response of hard and thick strata with the working face mining. For instance, in terms of the breaking law of hard thick strata, a mechanical model of Winkler orthogonal beam for a hard thick stratum according to its spatial structure and boundary foundation characteristics was established, and then its breaking span was reasonably predicted [11]. In consideration of the crack propagation speed of hard roof under the feature scale of a 
coalmine, the evolution of the roof breaking was analyzed, then the focal model during the hard roof breaking process was built, and the far-field vibration effect was quantitatively described [12]. The sudden collapse characteristics of hard roof in steep seam were analyzed by using physical simulation and numerical simulation [13]. The breaking-movement characteristics of a hard thick stratum and the rock burst-induced mode and mechanism were studied in the vicinity of fault $[1,2]$. Based on the field microseismic monitoring, the fracture of the overlying double-layer hard thick roof was studied, and the long-hole presplit blasting technology was proposed to weaken the strength of the hard thick roof [3]. Based on the Hoek Brown criterion, rock mechanics test of hard roof in repeated mining was carried out, and the relationship between failure strength and confining pressure of hard roof with different damage was analyzed [14].

On the response of hard thick rock breaking, the evolution process and morphological characteristics of bed separation under the key layer were studied, and then a mechanical analysis model and prediction method of maximum bed separation were proposed [8, 15]. The prediction model of overburden movement and deformation is established, and the strata behaviors of surface subsidence and crack were studied $[4,16]$. Based on the formation mechanism of abutment stress, a new theoretical calculation method of abutment stress with overlying multilayer hard thick strata occurrence was proposed $[17,18]$. In view of the mining advancing towards faults and passing through faults, the displacement-stress characteristics of hard thick stratum were studied, and then the inducing-mechanism of rockburst was revealed $[1,2]$. The evolution of mining fissures and abutment stress affected by the high-position main key stratum and these effects on gas migration were studied $[16,19]$. Based on the engineering background of panel 1411 in Huafeng coalmine, the mechanism of rockburst caused by hard roof was studied, and the characteristics of acoustic emission and other pieces of precursor information were analyzed [20]. The strength index of strata appearance was defined for the first time, a new method for grading and predicting the strength of pressure coming from the hard roof was proposed, and four quantitative indexes of different factors and levels were given [21].

Previous studies normally have analyzed the characteristics of the breaking and movement of the lower position main roof or the single-layer hard thick stratum and the causes of the dynamic disasters. In fact, when the occurrence position of hard thick stratum is high which is far away from the coal seam, the suspension above the goaf is large after mining activities, and the characteristics of stress displacement and energy release will vary significantly; moreover, when multilayer hard thick strata are overlaid, the movement of key layers affects each other and plays an important role in disturbance pressure or abutment stress. Hence, it is necessary to carry out a detailed study and analysis on the characteristics of strata behavior and its disaster induction mechanism under the condition of highposition multilayer hard thick strata.
In this paper, based on the mining background of overlying double-layer hard thick strata (DLHTS) above working face, the strata behaviors of DLHTS breaking and instability, such as overlying structure, plastic zone expansion, stress, and displacement distribution, and the precursor information-induced disasters are studied and analyzed, thereby revealing the interaction effect among the key layers and their breaking motion on the appearance of strata behaviors. Study results will provide a scientific basis for the prevention and control of dynamic disasters with hard thick strata conditions and provide an important guiding value for promoting the safe and efficient production of coalmines.

\section{Problems Arising and Engineering Background}

\subsection{Topic Problems Arising On-Site}

2.1.1. Support Pressure Increases in Working Face. During the mining period of panel 10414 of Yangliu coalmine, which has double layers (three layers in local position) of magmatic rock above coal seam marked as 10\#, from December 2010 to August 2011, the statistical analyses of mine pressure observation and support resistance are carried out in order to obtain the variation curve of working resistance of the typical support (marked as 11\#), as shown in Figure 1.

It can be seen that panel 10414 advances less than $160 \mathrm{~m}$ before April (corresponding to the gray area in Figure 1), the periodic weighting interval is monitored to be about $12 \mathrm{~m}$, and the average working resistance is lower than $30 \mathrm{MPa}$ as a whole of which the maximum is not more than $34 \mathrm{MPa}$; then, after April (corresponding to the blue area in Figure 1), the support resistance is significantly higher than that of before April, the average value exceeds $32 \mathrm{MPa}$, and the maximum value reaches $44 \mathrm{MPa}$. The primary reason is that the overlying strata maintain stable and have little effect on the supports due to small range mining before April, causing working resistance to slightly vary; however, after April, the goaf range expands obviously, causing the overlying magmatic rock to tend to its ultimate suspension span, thereby leading to the support significantly loaded and increase of support resistance. On April 17, when the face advances to about $220 \mathrm{~m}$, the large-scale suspended lower magmatic rock (LMR) breaks and moves sharply due to not bearing its own weight and overlying load, resulting in dynamic loading and large-area damage of support according to the field observations [11].

2.1.2. Water-Gas Blowout in Gas Drainage Hole. In panel 10414, 4 gas drainage boreholes, marked as 1\#, 2\#, 3-1\#, and $3 \#$, are arranged with the distance from open-off cut of 316 , 515,654 , and $721 \mathrm{~m}$, respectively, as shown in Figure 2(a). At 14:00 on July 16,2011 , the gas concentration reflected by 80 type pump on ground decreased from normal $90 \%$ to the lowest $20 \%$, and the extraction flow fluctuated sharply; then, at 22:00 on July 17, when the working face advances $525 \mathrm{~m}$, 


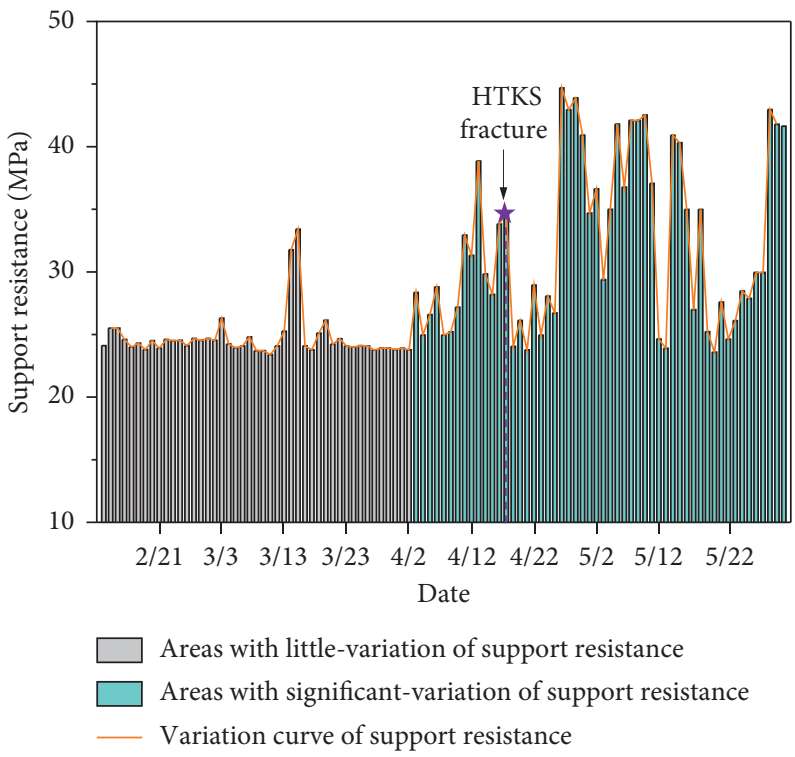

FIgURE 1: Variation curve of working resistance of typical support marked as 11\#.

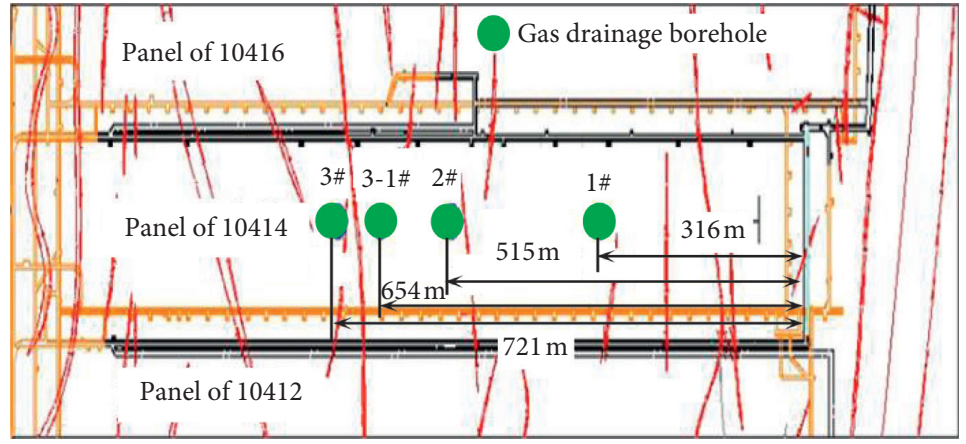

(a)

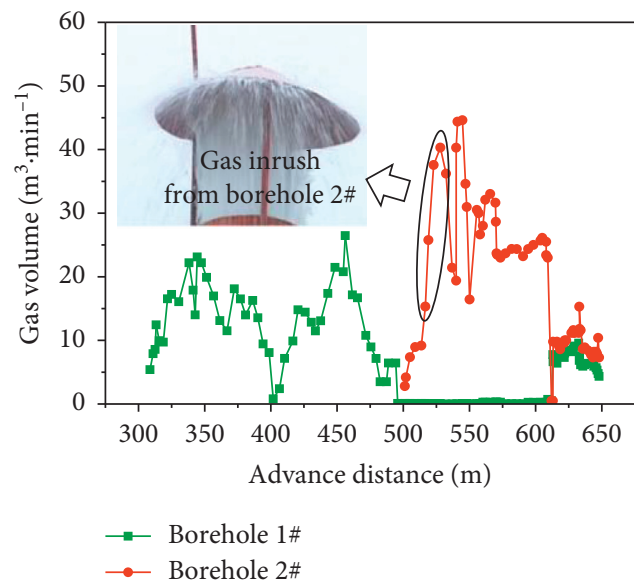

(b)

FIgURE 2: Dynamic accident of gas inrush in panel 10414 [22]. (a) Layout of gas drainage boreholes. (b) Relationship between gas inrush and advance distance.

the extraction concentration rose significantly from $20 \%$ to $100 \%$. Combined with the description from Figure 2(b), the extraction amount of 2\# gas drainage hole increases sharply with mining $500 \mathrm{~m}$, and then it reaches $40.15 \mathrm{~m}^{3} / \mathrm{min}$ along with water blowout phenomenon when the face advances $525 \mathrm{~m}$; with the face continuing to advance to $543 \mathrm{~m}$, the extraction amount reaches the peak value of $45.22 \mathrm{~m}^{3} / \mathrm{min}$ and then decreases subsequently.

According to the analysis of the field observations, due to the mining disturbance, the fracture and bed separation develop and expand below the magmatic rock, resulting in a large amount of free gas which is rich in the 10 coal seams previously moving upwards along these cracks and gathering in the bed separation. Then, the main key stratum (i.e., the upper magmatic rock (UMR)) will settle and move with the face advancing to $525 \mathrm{~m}$, and the bed separation will close rapidly with squeezing the gas and water in the bed separation, leading to water-gas blowout phenomenon through 2\# gas drainage hole [22].

From the aforementioned case studies of dynamic disasters of panel 10414, it can be seen that the breaking and instability movement of double layers of hard thick magmatic rock are the main cause of various dynamic disasters. Hence, it is necessary to carry out an in-depth and detailed study on the characteristics of strata behaviors and the precursor information of induced disasters with the 
occurrence of hard thick strata, especially with multilayer hard thick strata, so as to explore the interaction effect among the key layers and their breaking motion on the appearance of strata behaviors.

\subsection{Engineering Background of the Problem}

2.2.1. Overview of Panel 1061. Panel 1061 of Yangliu coalmine is taken as an engineering background. According to the drilling data of 9-5 and 9-10-2, the average dip angle of the coal seam is $8^{\circ}$ and thickness is $2.5 \mathrm{~m}$; moreover, the length and strike length are $189 \mathrm{~m}$ and $753 \mathrm{~m}$, and the depth of the coal seam is $-620--600 \mathrm{~m}$. The main roof is mainly fine and medium sandstone with a thickness of $4.20-28.83 \mathrm{~m}$. The comprehensive mechanized mining method is adopted for mining, and the free caving mode is used for roof management. This mining area is close to no. 104 mining area with similar geological conditions, so the weak burst liability identified by 104 mining area is applicable to 106 mining area.

\subsubsection{Overview of Magmatic Rocks Occurring above Panel} 1061. According to the drill data of boreholes 2010-4, 9-5, and 1061-1 in panel 1061 or its vicinity, double layers (three layers in local position) of magmatic rocks present above panel 1061, as shown in Figure 3. Herein, the thickness of UMR is $27-46 \mathrm{~m}$ with an average value of $29 \mathrm{~m}$ and an average distance of $355 \mathrm{~m}$ far away from 10\# coal seam; meanwhile, that of LMR is $27-60 \mathrm{~m}$ with an average of $31 \mathrm{~m}$ and $248 \mathrm{~m}$. The double layers of magmatic rock also determined key strata similar to those in panel 10414 . Moreover, their uniaxial compressive and tensile strengths are $113.6 \mathrm{MPa}$ and $6.25 \mathrm{MPa}$, and the average distance between the two layers is $63 \mathrm{~m}[23,24]$.

\section{Breaking Analysis of Overlying Magmatic Rock in Panel 1061}

According to drill data of boreholes 2010-4, 9-5, and 1061-1 in panel 1061 or its vicinity, the thickness of magmatic rock and the distance between magmatic rock and coal seam vary greatly. Hence, in order to improve the accuracy and rationality of the calculation, this section takes the average value of the exposed magmatic rock thickness and the distance between magmatic rock and coal seam, as listed in Table 1.

The analysis of the breaking span of magmatic rock can be divided into two aspects: the advancing direction and the strike direction of the working face. The former is to calculate the initial weighting step of the working face and the latter is to calculate the ultimate stable span when magmatic rock breaking; that is, when the span of overlying magmatic rock strata in the strike direction of the working face is large, unstable breaking may occur.

3.1. Calculation of Ultimate Stable Span of Magmatic Rock in Strike Direction. With the panel 1061 mining, the overlying magmatic rock will subside and move with the goaf increase.

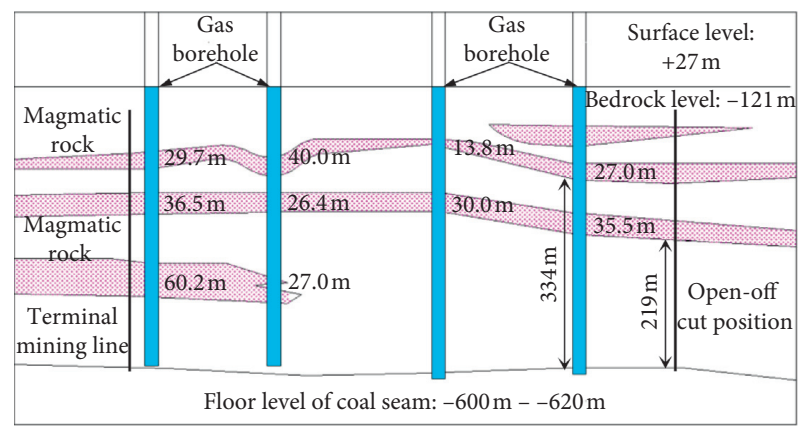

Figure 3: Sectional drawing of magmatic rock and borehole in panel 1061 [23].

TABLE 1: Parameters of double layers of magmatic rock above panel 1061.

\begin{tabular}{lccc}
\hline $\begin{array}{l}\text { Magmatic } \\
\text { rocks }\end{array}$ & $\begin{array}{c}\text { Thickness } \\
h(\mathrm{~m})\end{array}$ & $\begin{array}{c}\text { Distance } \\
\text { from coal } \\
\text { seam 10\# } \\
\sum H(\mathrm{~m})\end{array}$ & $\begin{array}{c}\text { Distance between two } \\
\text { layers }(\mathrm{m})\end{array}$ \\
\hline $\begin{array}{l}\text { Upper } \\
\text { magmatic } \\
\text { rock (UMR) }\end{array}$ & 29 & 326 & \\
$\begin{array}{l}\text { Lower } \\
\text { magmatic } \\
\text { rock (LMR) }\end{array}$ & 31 & 232 & 63 \\
\hline
\end{tabular}

At this time, the magmatic rock can be regarded as the fixed support beam in the strike direction of the face. When it reaches the ultimate suspension span and breaks, considering the influence of overburden fracture angle $[25,26]$, the ultimate stable span in strike direction $b_{0}$ can be expressed as

$$
\left\{\begin{array}{l}
b=h \sqrt{\frac{2 k R_{t}}{q}}, \\
b_{0}=b+2 \sum H \cot \theta,
\end{array}\right.
$$

where $b$ is the ultimate span of magmatic rock in strike direction, $m ; k$ is the cracking coefficient of rock which reflects the development of fractures in rocks, $k=0.25-0.75$ [25]; $\theta$ is the fracture angle of strata, $\theta=75^{\circ}[25,26]$.

LMR is an inferior key stratum; it needs to bear its selfweight and the overburden load between the two magmatic rocks, as expressed by $q_{l}=25 \mathrm{kN} \mathrm{m}^{-3} \times 94 \mathrm{~m}=2.35 \mathrm{MPa}$, while the UMR is the main key stratum, resulting in bearing its self-weight and all the strata load on it, as calculated by $q_{u}=25 \mathrm{kN} \mathrm{m}^{-3} \times 384 \mathrm{~m}=9.60 \mathrm{MPa}$. Hence, based on a double-layer magmatic rock being regarded as fixed support beams without considering the foundation effect of underlying strata, the ultimate span of two layers of magmatic rock in strike direction is obtained by substituting the above parameters into equation (1) as $b_{0 l}=160.10-186.27 \mathrm{~m}$ (LMR) and $b_{0 u}=191.27-203.40 \mathrm{~m}$ (UMR).

Due to the length of panel 1061 of $189 \mathrm{~m}$, it is larger than the ultimate span of LMR and smaller than that of UMR 
which indicates that the LMR will break with a certain mining distance, but the UMR may not. However, if the adjacent working face continues to be mined, the UMR will also break once the suspension length of UMR caused by two adjacent working faces mined exceeds its ultimate span.

It should be noted that the parameter $q$ in equation (1) only considers the self-weight and its follower layers when calculating LMR breaking span and does not consider the disturbance load caused by the UMR suspension [18]. Hence, the actual ultimate span should be smaller than the calculated value; that is, it is more likely to break.

3.2. Calculation of Initial Weighting Step of Magmatic Rock. According to the comprehensive histogram of 106 mining area and thin plate theory, the magmatic rock can be regarded as thin plates because the ratio of its thickness to the strike span meets certain conditions, and then the initial weighting step of magmatic rock is obtained [25]:

$$
\begin{aligned}
& \left\{\begin{array}{l}
\alpha=\frac{\beta}{\sqrt{3-(2 \beta / b)}}, \\
\beta=\sqrt{\frac{4 R_{t} k h^{2}}{1.3 \gamma H \cos \alpha}},
\end{array}\right. \\
& L=a+2 \sum H \cot \theta,
\end{aligned}
$$

where $a$ is the LMR ultimate span in advancing direction, $m$; $L$ is the initial weighting step of LMR, $m$; $H$ is the thickness of LMR and its follower layer, $m ; \gamma$ is the strata density, $2500 \mathrm{kN} / \mathrm{m}^{3}$; and $\alpha$ is the dip angle of the coal seam, $8^{\circ}$.

Combining equations (1)-(3), the initial weighting step of LMR can be obtained as $L=188.42-233.39 \mathrm{~m}$. Results show that the advancing distance $L$ is close to the length of panel 1061 (i.e., $189 \mathrm{~m}$ ), resulting in forming the phenomenon of "one-time square" on the project site. Hence, the strata behaviors are obvious and release a large amount of elastic strain energy, which may pose a serious threat to the equipment and safety production and should strengthen the monitoring and prevention of the face.

\section{Mining Responses before and after Magmatic Rock Breaking}

According to the aforementioned analysis, the structural evolution of overlying strata and the strata behaviors may be different from those of conventional strata affected by the occurrence of hard thick strata. Hence, during the mining process of panel 1061, mining responses before and after the magmatic rock breaking are analyzed by using numerical simulation and physical simulation, in order to directly describe and quantify the effect of hard thick strata on the mining responses.

4.1. Evolution Analysis of Mining Stress and Plastic Zone. According to the actual geological condition of panel 1061, a UDEC numerical model with the size of $700 \mathrm{~m}$ (length) $\times$
$450 \mathrm{~m}$ (height) is established to simplify several strata in order to simulate the mining state of $550 \mathrm{~m}$, and then the mining stress evolution and plastic zone expansion affected by the DLHTS breaking are studied. Herein, the model boundary, loading method, and conditions are all applied, referring to the actual conditions and previous references [27-30]. Limited by the length of the paper, this section will directly show and describe the nephogram of mining stress and plastic zone before and after the DLHTS breaking.

4.1.1. Evolution Analysis of Plastic Zone. Affected by the mining activities, the fractures in the overlying rock above goaf develop and expand, which shows that the plastic zone grows and expands until the overlying strata completely break and move. Figure 4 shows the distribution and evolution of plastic zone during the mining process with several typical mining states.

From Figure 4, it can be seen that, with the goaf range increasing, the plastic zone is constantly expanding, and tensile, shear, or volume failures in different locations and regions occur. However, due to the block and control of the structure of magmatic rock, the development of plastic zone before and after the magmatic rock breaking shows a certain difference.

In Figures 4(a) and 4(b), when the working face advances $160 \mathrm{~m}$, the fracture mainly occurs below the LMR and only shows horizontal expansion due to block effect of LMR, leading to plastic zone gathering LMR beneath and presenting much tensile, shear, or volume failure in the model; at this moment, LMR is in the state of energy accumulation and stress rises due to large-scale suspension, which provides sufficient energy conditions for the subsequent dynamic disasters. As the face advancing to $190 \mathrm{~m}$ shown in Figure 4(c), fractures develop in LMR caused by its bending and deformation because its suspension reaches its ultimate span and drives the upper strata to move harmoniously, resulting in the plastic zone obviously extending to the bottom of UMR, but the LMR can still maintain relative stability. As shown in Figure 4(d), the fracture in LMR continues to develop and the obvious tensile fracture through LMR occurs with the face advancing to $220 \mathrm{~m}$, and the range of plastic zone expands obviously to the bottom of UMR, which indicates that the LMR has been completely broken and drives the upper layer to move harmoniously. At this time, attention should be paid to the energy released by the breaking and violent movement of magmatic rock and its induced harm. Meanwhile, the simulation results of LMR breaking $(220 \mathrm{~m})$ are basically consistent with the theoretical analysis results (188.42-233.39 m).

As shown in Figure 4(e), we can see that a new plastic failure zone through the whole LMR is formed which shows that LMR breaks periodically and drives its upper layer to move synchronously which lead to an obvious vertical tensile fracture in UMR, indicating that the UMR begins to bend and break but still has enough bearing capacity. In Figures $4(\mathrm{f})$ and $4(\mathrm{~g})$, the LMR breaks periodically for several times with the face advancing to $370 \mathrm{~m}$ and $550 \mathrm{~m}$, which provides enough space for UMR to move and makes it 


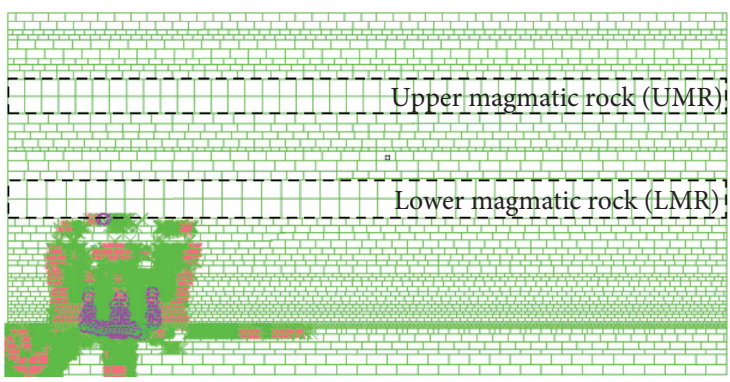

Rock mass damaged by shear or volume failure $\left({ }^{*}\right)$

Rock mass returned to elastic state after yielding $(x)$

Rock mass damaged by tensile failure $(\bigcirc)$

(a)

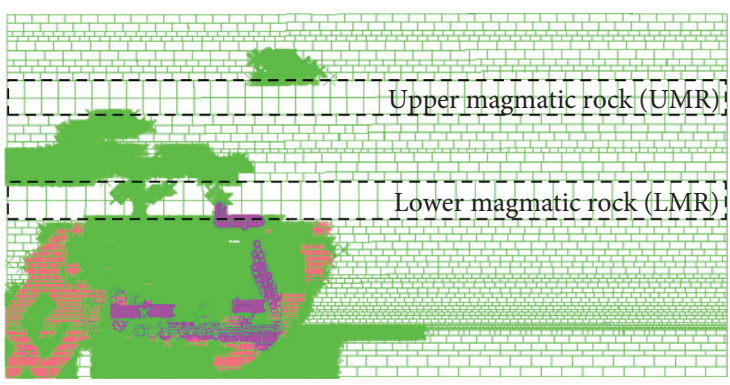

Rock mass damaged by shear or volume failure $\left(^{*}\right)$ Rock mass returned to elastic state after yielding $(x)$ Rock mass damaged by tensile failure $(\bigcirc)$

(c)

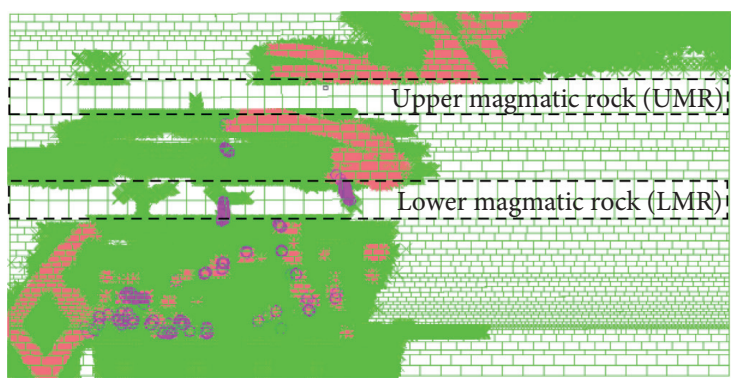

Rock mass damaged by shear or volume failure $\left(^{*}\right)$

Rock mass returned to elastic state after yielding $(x)$ Rock mass damaged by tensile failure $(\bigcirc)$

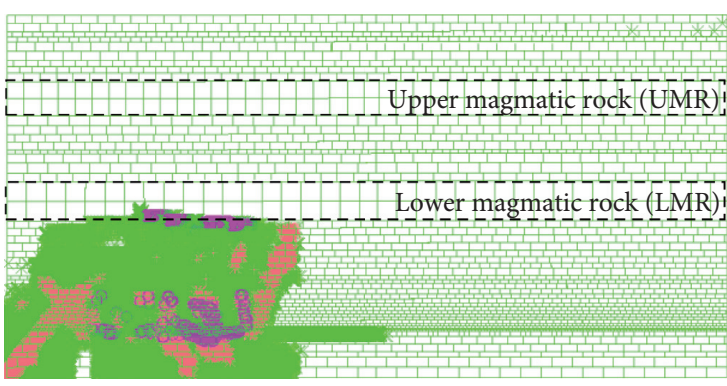

Rock mass damaged by shear or volume failure $\left({ }^{*}\right)$ Rock mass returned to elastic state after yielding $(x)$ Rock mass damaged by tensile failure $(\bigcirc)$

(b)

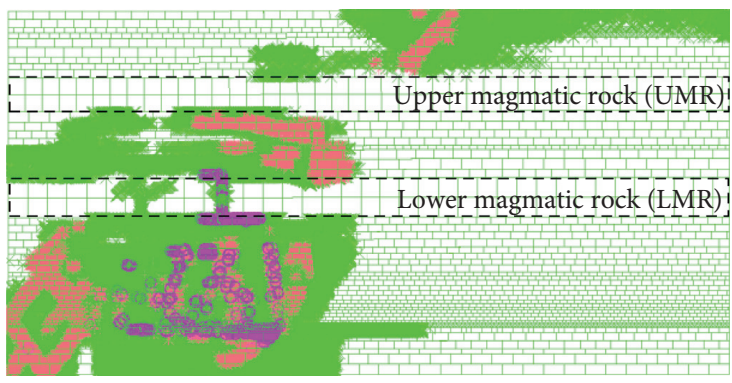

Rock mass damaged by shear or volume failure $\left(^{*}\right)$ Rock mass returned to elastic state after yielding $(x)$ Rock mass damaged by tensile failure $(\bigcirc)$

(d)

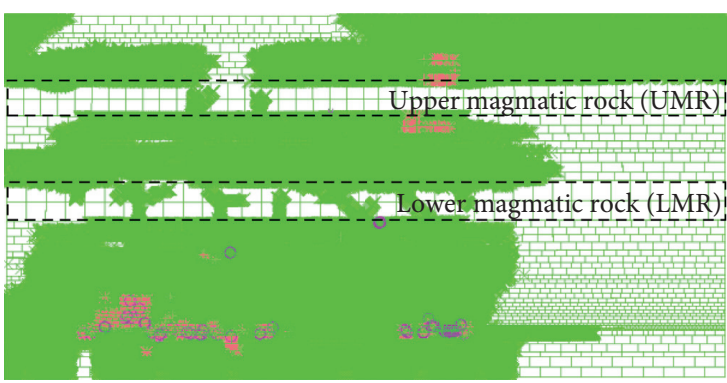

Rock mass damaged by shear or volume failure $\left(^{*}\right)$

Rock mass returned to elastic state after yielding $(x)$ Rock mass damaged by tensile failure $(\mathrm{O})$

(e)

(f)

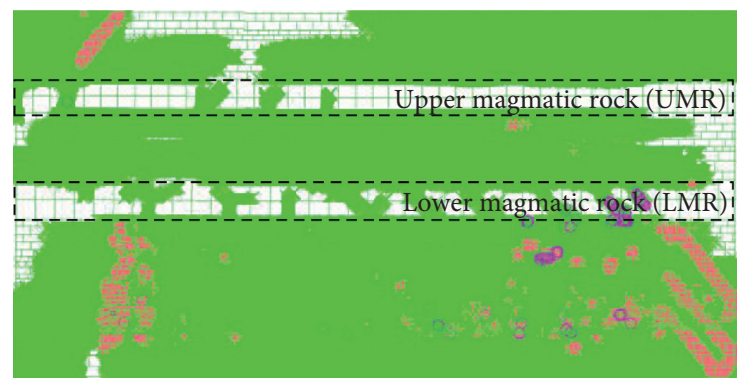

Rock mass damaged by shear or volume failure $\left(^{*}\right)$

Rock mass returned to elastic state after yielding $(x)$

Rock mass damaged by tensile failure $(\bigcirc)$

Figure 4: Variation of plastic zone during the mining process. (a) $70 \mathrm{~m}$. (b) $160 \mathrm{~m}$. (c) $190 \mathrm{~m}$. (d) $220 \mathrm{~m}$. (e) $250 \mathrm{~m}$. (f) $370 \mathrm{~m}$. (g) $550 \mathrm{~m}$. 
initial and periodical break (reflected by multiple vertical plastic zones running through the UMR); it indicates that the UMR is basically completely breaking and we should pay attention to the impact of UMR breaking and its secondary instability effect on LMR.

4.1.2. Evolution Analysis of Mining Stress. Mining activities break the original stress balance and produce stress concentration or stress reduction in surrounding rocks, which has a certain influence on mining face, roadway layout, coal pillar reservation, and so on. In particular, high-stress concentration is likely formed with the occurrence of hard thick stratum because of the characteristics of mechanical and structure. Figure 5 shows the nephogram of stress distribution and evolution with typical mining states.

It can be seen that, due to the occurrence of two layers of magmatic rock, the influence range and value of front abutment stress before breaking will continue to increase, while after breaking the energy will be released at the same time. Combined with the distribution of the plastic zone in Section 4.1.1, the variation of tensile stress in magmatic rock is analyzed as an example. During the mining process of $190 \mathrm{~m}$, the LMR continue to suspend, affected by mining activities and the abutment stress rises, and the LMR above the goaf gradually runs into the stress reduction zone; then, the LMR is bent and deformed with the face advancing to $190 \mathrm{~m}$, resulting in a large range of tensile failure zone, and the maximum tensile stress reaches $9 \mathrm{MPa}$, as shown in Figure $4(\mathrm{c})$ and $5(\mathrm{c})$. When it continues to advance to $220 \mathrm{~m}$, the LMR appears a tensile fracture throughout the whole layer (Figure $4(\mathrm{~d})$ ) which presents that it has been broken, the maximum tensile stress can reach $13 \mathrm{MPa}$ (Figure 5(d)), and it drives the upper layer to move synchronously. Then, the periodic breaking of LMR drives the synchronous movement of its upper strata with the face mining $250 \mathrm{~m}$ so that the UMR suspension increases and the tensile fracture appears in UMR (Figure 4(e)); at present, the maximum tensile stress is only $8 \mathrm{MPa}$ (Figure $5(\mathrm{e})$ ) and the UMR still has enough bearing capacity. When the face advances to $370 \mathrm{~m}$, the plastic failure zone in UMR runs through the whole layer and presents the initial breaking, and the maximum tensile stress rises to $12 \mathrm{MPa}$ (Figure 5(f)); however, the value becomes $1.1 \mathrm{MPa}$ (Figure $5(\mathrm{~g})$ ) when the face advances to $550 \mathrm{~m}$.

As shown in Figure 6, the variation of tensile stress before and after double layers of magmatic rock breaking can be divided into three stages. Stage $a$ corresponds to the mining process of the first $220 \mathrm{~m}$; the LMR is continuously suspended, bent, and subsided, and the tensile stress consequently rises with the maximum of $13 \mathrm{MPa}$; this process shows that stress concentration and energy accumulation are affected by LMR large-scale suspension, until the tensile stress of LMR exceeds its ultimate strength and it breaks completely with advancing to $220 \mathrm{~m}$ (as shown in Figure 4(d)). Subsequently, the tensile stress decreases sharply, and the high concentration stress decreases and the energy is released; however, the UMR begins to span, bend, and settle continuously because of LMR periodic breaking, and the tensile stress increases and the maximum recovers to $12 \mathrm{MPa}$; this process shows stress concentration and energy accumulation caused by UMR suspension and corresponds to the stage $b$ (advancing to $370 \mathrm{~m}$ ). As the face continues to advance, the UMR experiences the initial and periodic break, leading the tensile stress to drop suddenly, and the elastic strain is released, corresponding to the stage $c$ in Figure 6.

4.2. Characteristics of Structure and Movement of Double Layers of Magmatic Rock. In order to show the structure and movement characteristics of hard thick strata more intuitively, taking the double layers of magmatic rock of Yangliu coalmine as the prototype, then a physical model test is carried out based on similarity theory with the model size of $3.0 \mathrm{~m} \times 0.4 \mathrm{~m} \times 1.5 \mathrm{~m}$ (length $\times$ width $\times$ height), and the similarity coefficients are 1/200 (geometry), 1/300(strength), and 1/1.5 (density). In the model test, river sand, calcium carbonate, and gypsum are chosen as equivalent materials, and the actual strata strength is needed to be converted into the simulated strength of equivalent material according to the similarity coefficients; then, the optimum material ratio of each stratum in model is determined through the literature reference and multiple comparative tests [31-33]. In addition, the designed mining height and depth in model are $8 \mathrm{~m}$ and $600 \mathrm{~m}$ and can simulate to advance to $500 \mathrm{~m}$; moreover, some iron needs to be imposed on top of the model to compensate for the upper failed strata to simulate [34]. Record the structure and movement of overburden by photography.

4.2.1. Evolution of Overburden Structure. During the mining process, overlying strata will collapse and move, but it is significantly affected by the structure and mechanical characteristics of hard thick strata. Hence, several typical mining states are chosen to study the structural shape and evolution of overburden under the effect of hard and thick strata, as shown in Figure 7.

It can be seen that double layers of magmatic rock play a decisive role in the development of bed separation and structural evolution of the overburden, and they interact with and influence each other. In Figure 7(a) and 7(b), during the mining process of $220 \mathrm{~m}$, the overlying strata are moved, and the bed separation develops to the bottom of LMR and expands laterally, thus resulting in LMR beginning to bending and subsidence with obvious tensile failure occurring with advancing to $220 \mathrm{~m}$; the results have good agreement with the development law of plastic zone in Figure 4(a)-4(c), and the bed separation below provides enough space for LMR moving and breaking. When the face advances to $236 \mathrm{~m}$, as shown in Figure 7 (c), the LMR makes initial breaking and instability, driving its upper strata to move synchronously because of the fractures development at both ends of LMR and then running through the whole layer; the LMR and its follower layer move significantly, and the bed separation develops rapidly to the bottom of UMR, which is similar to the description results of Figure 4(d). As the face continues to advance to $330 \mathrm{~m}$ (in Figure $7(\mathrm{~d})$ ), the periodic breaking of LMR 


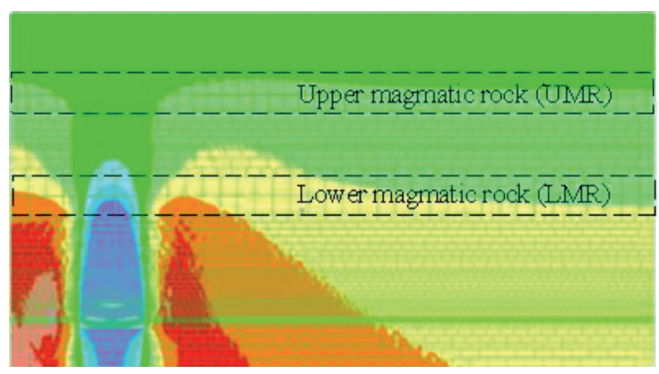

(a)

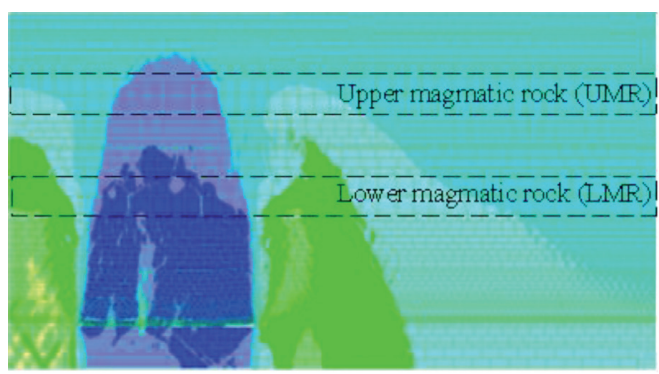

(c)

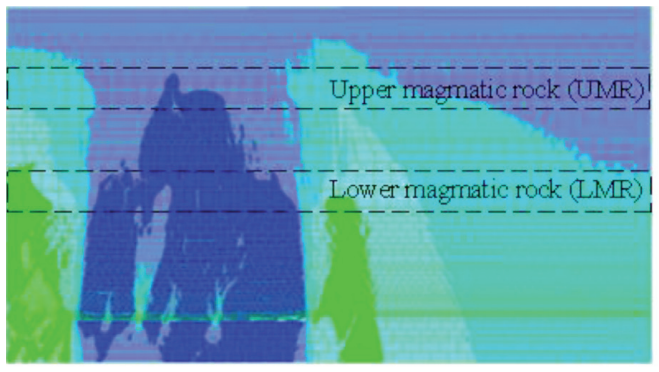

(e)

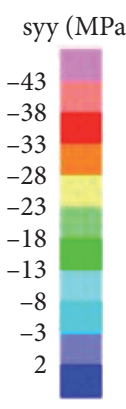

syy (MPa)

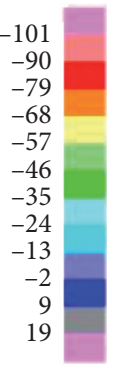

syy (MPa)

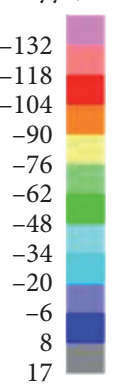

17

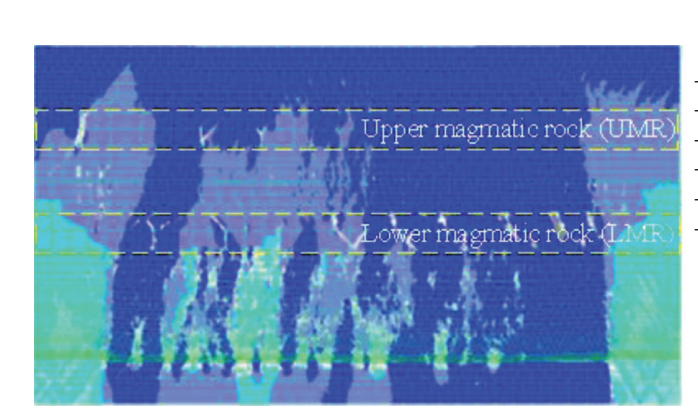

(g)
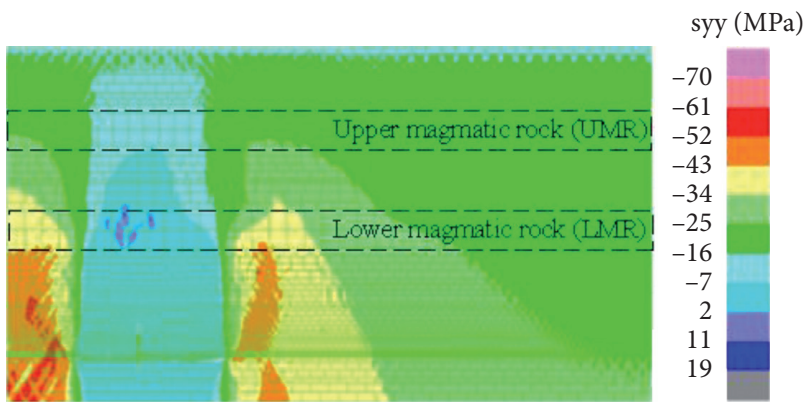

(b)
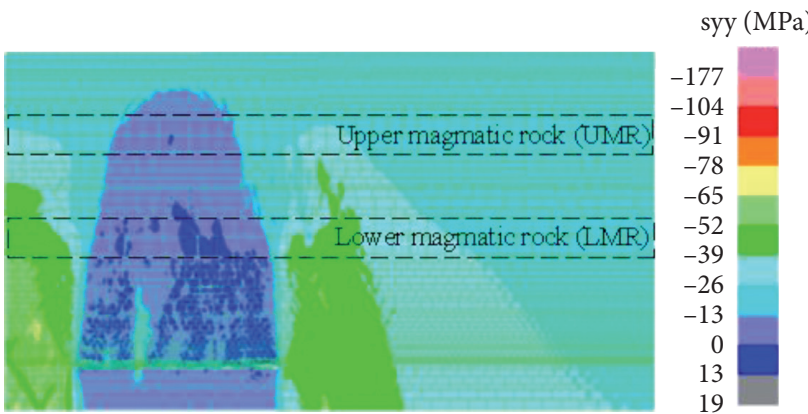

(d)
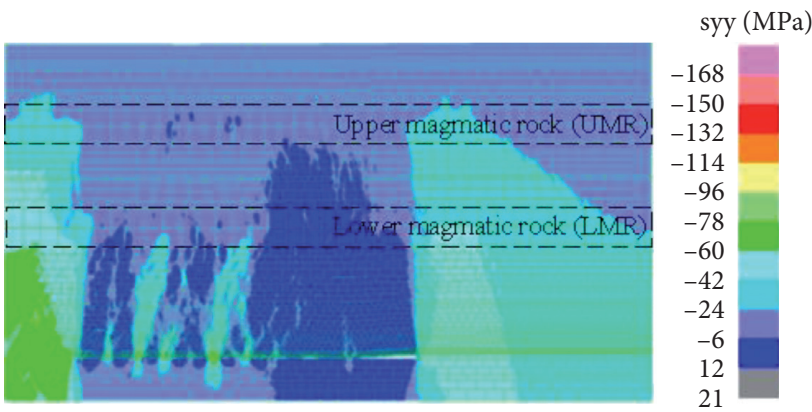

(f)

syy (MPa)

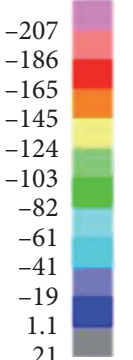

Figure 5: Stress distribution and evolution with typical mining states. (a) $70 \mathrm{~m}$. (b) $160 \mathrm{~m}$. (c) $190 \mathrm{~m}$. (d) $220 \mathrm{~m}$. (e) $250 \mathrm{~m}$. (f) $370 \mathrm{~m}$. (g) $550 \mathrm{~m}$.

increases the suspension span of UMR and provides enough space for UMR breaking; and then the UMR and its follower layer subside and move with the face advancing to $410 \mathrm{~m}$, resulting in the top of the model presenting obvious displacement which verifies that the UMR is the main key stratum and can control all strata above it; the results are consistent with the development law of plastic zone in Figure 4(e). When the face continues to advance to $470 \mathrm{~m}$, several times periodic breaking of LMR appears and UMR suspension span increases, causing the UMR initial breaks and all follower layers move synchronously and significantly, which is similar to the description in Figure 4(f), 


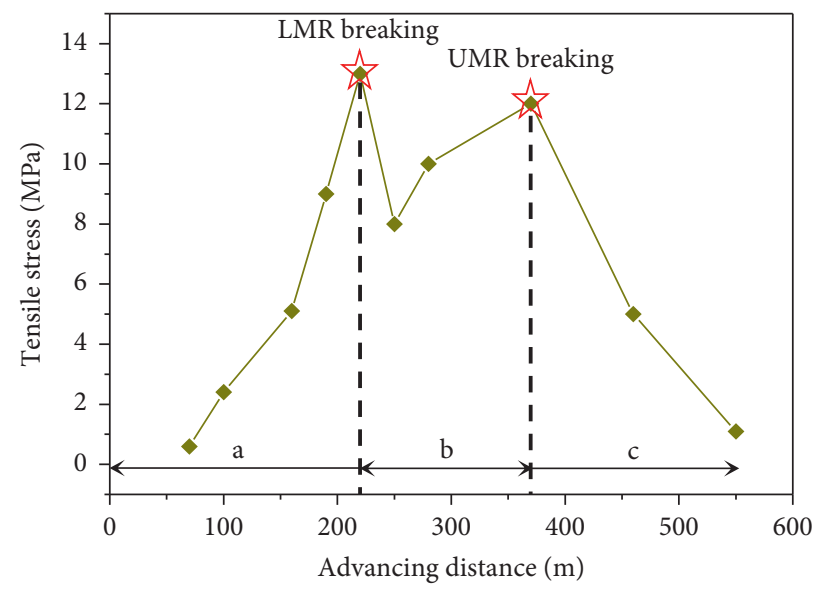

FIGURE 6: Variation curve of tensile stress before and after double layers of magmatic rock breaking.

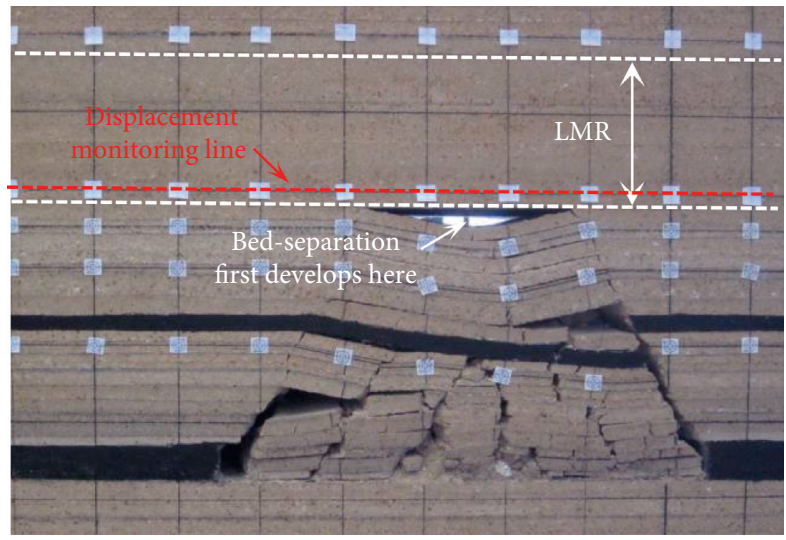

(a)

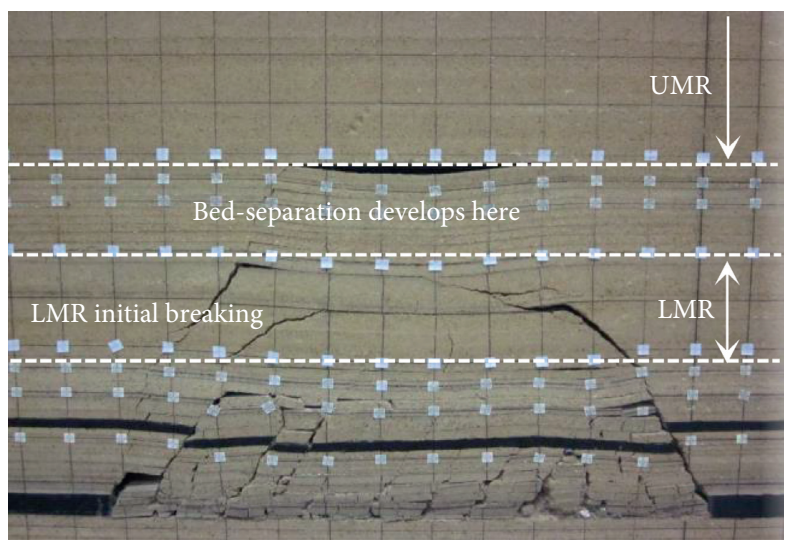

(c)

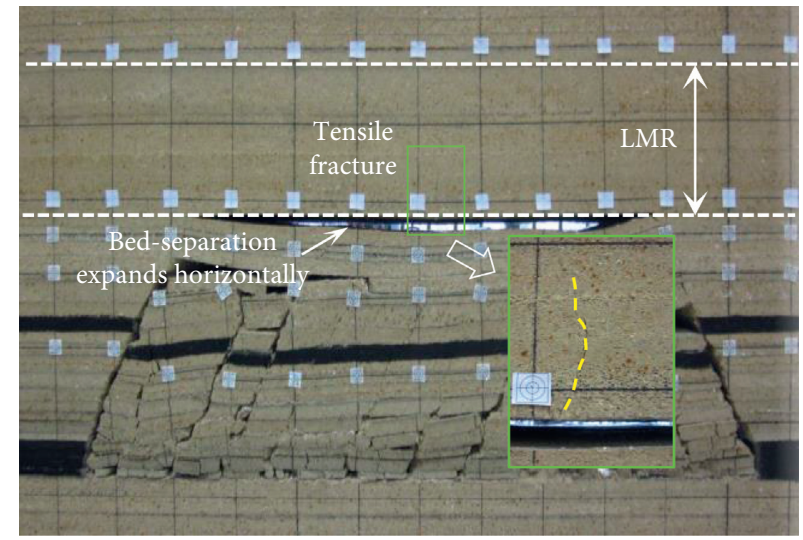

(b)

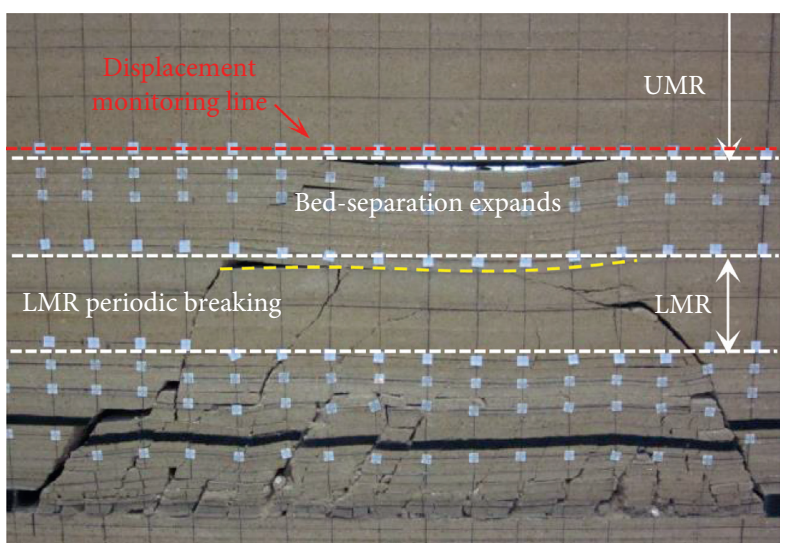

(d)

FIgURE 7: Continued. 


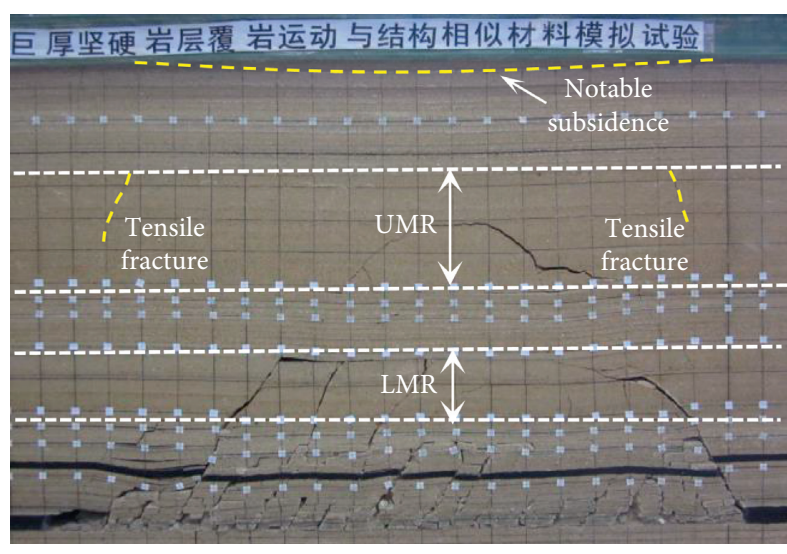

(e)

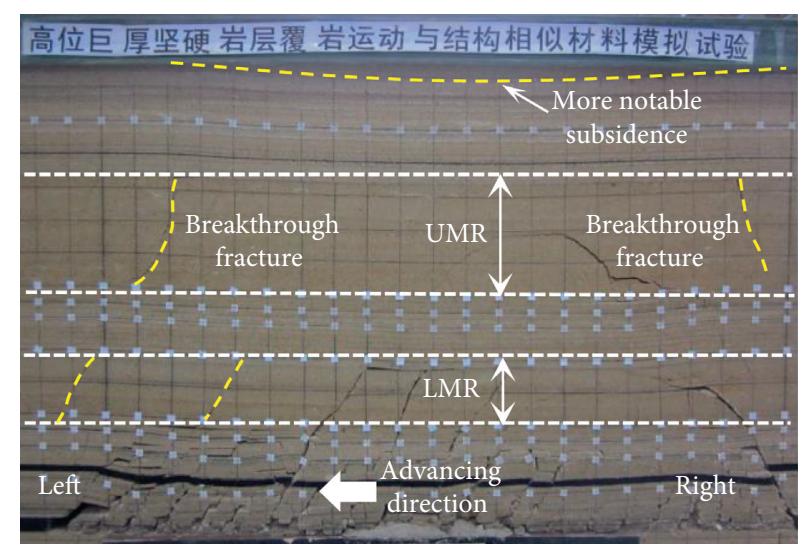

(f)

FiguRE 7: Structural evolution of overburden with several typical mining states. (a) $120 \mathrm{~m}$. (b) $220 \mathrm{~m}$. (c) $236 \mathrm{~m}$. (d) $330 \mathrm{~m}$. (e) $410 \mathrm{~m}$. (f) $470 \mathrm{~m}$.

thus releasing a large amount of elastic strain energy with the UMR breaking and affecting the movement and stability of the LMR.

\subsubsection{Movement Analysis of Double Layers of Magmatic} Rock. In order to better quantitatively describe the movement of double layers of magmatic rock, two displacement monitoring lines are set at the bottom of two layers of magmatic rock in the physical model, and these specific locations are calibrated with the red-dotted line in Figure 8(a) and 8(b); then, a reflector is fixed with $10 \mathrm{~cm}$ interval, and the total station without prism is used for displacement measurement. Figure 8 shows the movement variations of the two layers of magmatic rock before and after their breaking.

From Figures $7(\mathrm{a})-7(\mathrm{c})$ and $8(\mathrm{a})$, we can see that when the working face advances to $220 \mathrm{~m}$, the LMR reaches ultimate span and begins to bend and settle with small displacement; then, it advances to $236 \mathrm{~m}$, and LMR suddenly breaks and loses stability, causing its displacement to sharply increase with the maximum value of $5.50 \mathrm{~m}$ which is likely to release a large amount of elastic strain energy suddenly, thus inducing dynamic disasters, such as rockburst and shock bump.

As shown in Figures $7(\mathrm{~d})-7(\mathrm{f})$ and $8(\mathrm{~b})$, when the working face continues to advance to $330 \mathrm{~m}$, the UMR shows slight deformation and settlement affected by the initial and periodic breaking of LMR; while it advances to $340 \mathrm{~m}$, due to the heterogeneity characteristic and weak plane occurrence in magmatic rock, the suspended part of UMR is sheared and destroyed in advance, which presents direct collapse and settlement with the maximum displacement of $5.0 \mathrm{~m}$; it is easy to cause such dynamic problems as water-gas inrush in the bed separation and necessary to strengthen the monitoring and protection brought by the weak plane of rock mass. Then, the UMR shows obvious bending and settlement with the face advancing of $410 \mathrm{~m}$, while it breaks and loses stability while advancing to $470 \mathrm{~m}$ and its maximum displacement rises to $5.6 \mathrm{~m}$, thus easily resulting in the release of elastic strain energy and inducing dynamic disasters. Hence, with the hard thick strata occurrence above the working face, it is easy to cause a sudden and sharp move of hard thick rock, and the displacement presents mutation characteristic.

Figure 9 shows the movement states of LMR before and after UMR breaking. It can be seen that, before UMR completely breaks (corresponding to advancing $410 \mathrm{~m}$ ), the LMR has experienced multiple periodic breaking and after a long time of settlement and compaction, its displacement is basically stable; however, the LMR is still in a cantilever state before next periodic breaking at this time. After UMR complete breaking (corresponding to advancing to $470 \mathrm{~m}$ ), the movement range and displacement of LMR increase significantly as depicted in Figure 9 with blue-dotted box, and the displacement of LMR that has moved previously also increases slightly; it shows that the breaking and movement of UMR not only can promote the periodic breaking of LMR but also may cause the secondary impact on its stability.

In conclusion, the overlying high-position magmatic rocks play a role of bearing, blocking, and controlling, and they have a significant influence on the mining responses (i.e., overlying rock structure, plastic zone expansion, stress, and displacement distribution) before and after they break. Prior to DLHTS breaking, the horizontal development of stress concentration zone and the plastic zone is controlled, and the movement of overburden is gentle, while during the breaking process, the stress drops abruptly, the plastic area expands longitudinally rapidly, the structure of the magmatic rock is unstable, the displacement of overburden increases obviously, and the energy release is sharp. Meanwhile, the DLHTS can interact and influence each other, that is, the LMR breaking can provide sufficient space for UMR movement, while the UMR breaking can promote the LMR periodic breaking in turn and cause its secondary instability. Hence, when DLHTS occurs above the working face, the direct impact caused by DLHTS breaking and movement should be paid more attention to and also the LMR periodic breaking and the secondary instability caused by the UMR breaking. Generally speaking, compared with the influence of single-layer hard thick strata breaking, the 


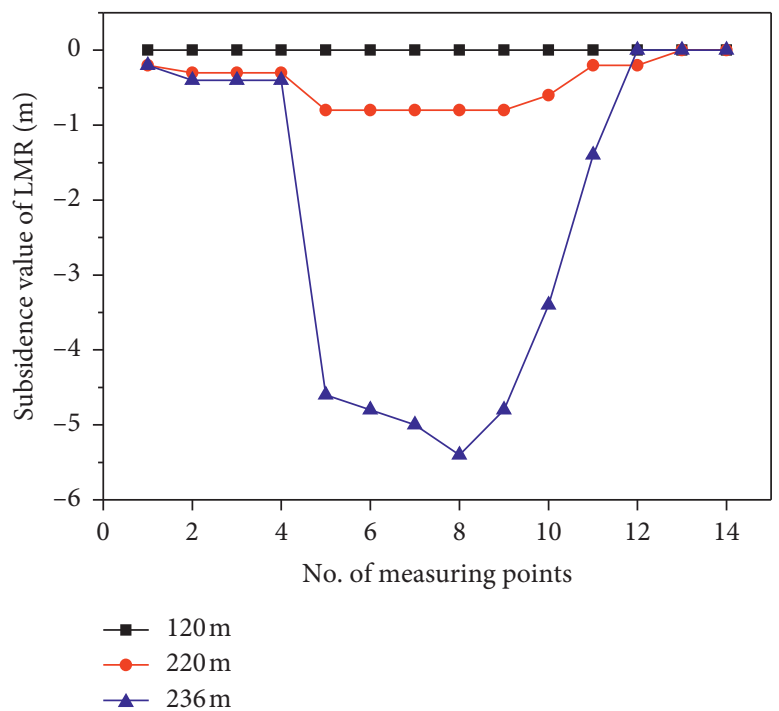

(a)

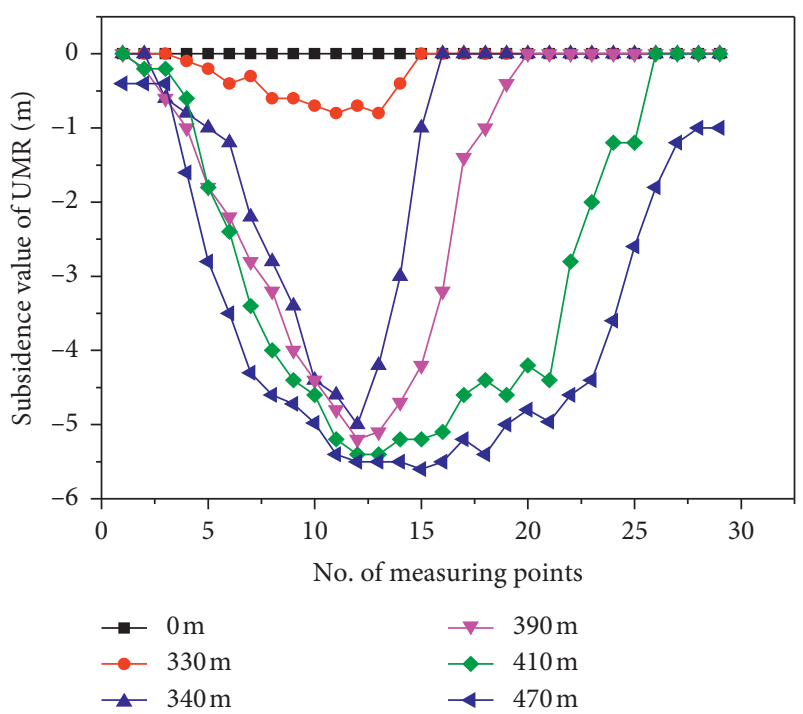

(b)

FIGURE 8: Movement variations of two layers of magmatic rock before and after their breaking. (a) LMR movement before and after its breaking. (b) UMR movement before and after its breaking.

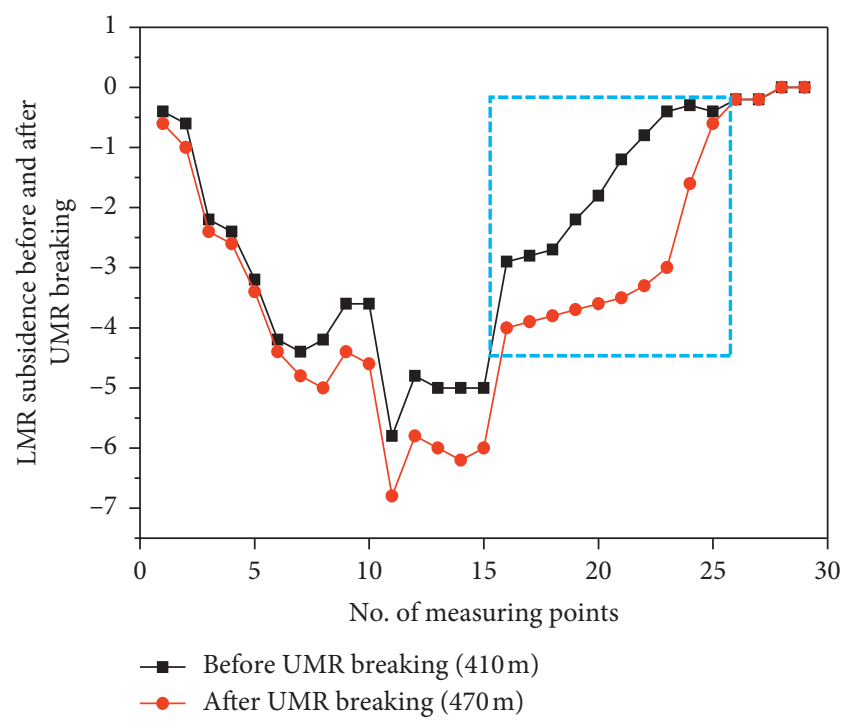

FIGURE 9: Effect of UMR on LMR before and after UMR breaking.

strata behaviors produced by DLHTS breaking and instability are much stronger, and it is easier to induce strong dynamic pressure phenomena, such as strong support dynamic load, rockburst, shock bump, and coal and gas outburst.

\section{Engineering Case}

In this section, the support pressure in panel 1061 will be monitored in order to further explain the influence of breaking and instability of hard thick strata on the appearance of strata behaviors. In panel 1061, 12 sets of pressure monitors for fully mechanized support are installed, which are, respectively, arranged on hydraulic supports marked as 5\#, 15\#, 25\#, 55\#, 65\#, 75\#, 85\#, 95\#, $105 \#$, and 115\# from the head to the tail. Figure 10 shows the variation curve of typical support pressure monitored in June 2014.

According to Figure 10 depiction and the information provided by the coalmine, the pressure of most supports increased after June 18, among which the pressure of 5, 15, $25,55,65,75$, and $115 \#$ supports increased significantly, especially after June 23 , the pressure of some supports has exceeded $40 \mathrm{MPa}$, and the maximum of $65 \#$ support can reach $48.4 \mathrm{MPa}$. By referring to the field monitoring and analysis, it is found that initial breaking happens to the highposition hard thick magmatic rock after June 23 , and the magmatic rock lost its stability and moved violently, causing the hydraulic support to press in a large range and dynamic loading phenomenon obvious; at present, the dynamic pressure coefficient of the supports is more than 2.0 in 15, 25, 55,95 , and 105\# supports, and maximum value has reached 2.58 in support 95\#, as shown in Table 2. The results show that the high-position hard thick magmatic rock loses stability and moves rapidly after breaking, resulting in producing strong dynamic impact and releasing a large amount of elastic strain energy; this conclusion has good agreement with the results of Sections 3 and 4. Then, the energy transmits to the surrounding rock in the form of shock wave, which causes the strata behavior of strong dynamic pressure of the supports.

From the case studies of panel 10414 in Section 2.1, the breaking and instability of double layers of hard thick magmatic rock are the main cause of various dynamic disasters, which seriously threatens the safe production during coal mining. Meanwhile, the analysis of Section 4 shows that when DLHTS occur above the working face, the hard thick stratum can interact and influence each other, which is likely to cause complex or composite dynamic disasters, such as 


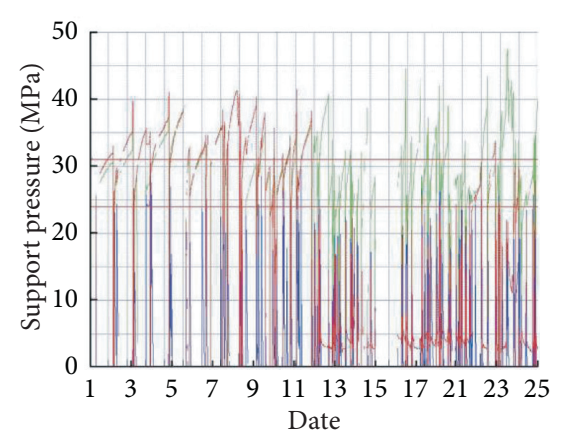

(a)

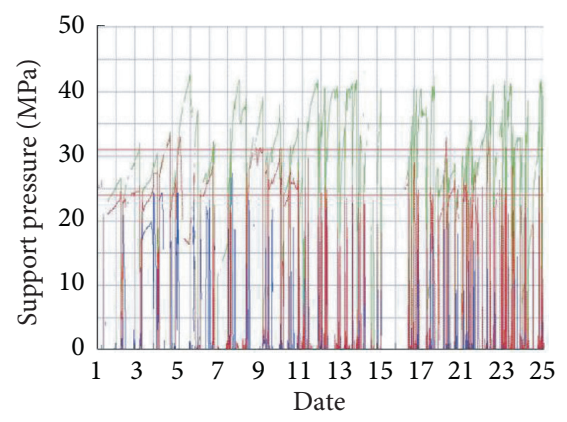

(d)

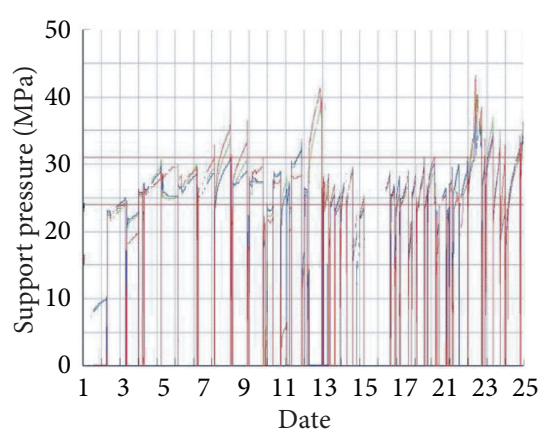

(b)

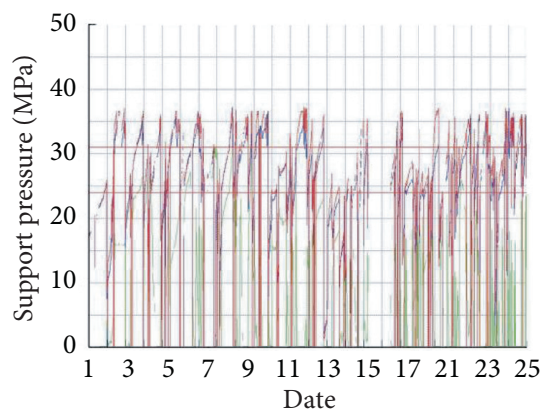

(e)

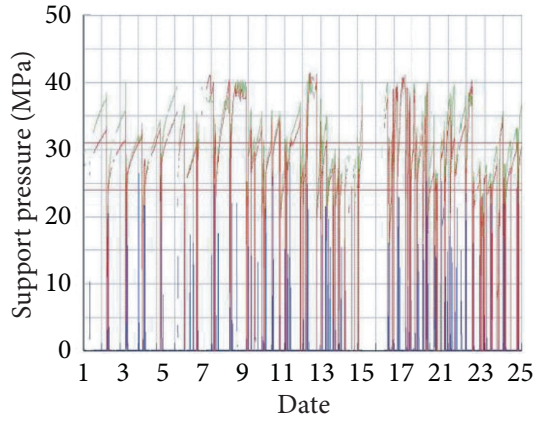

(c)

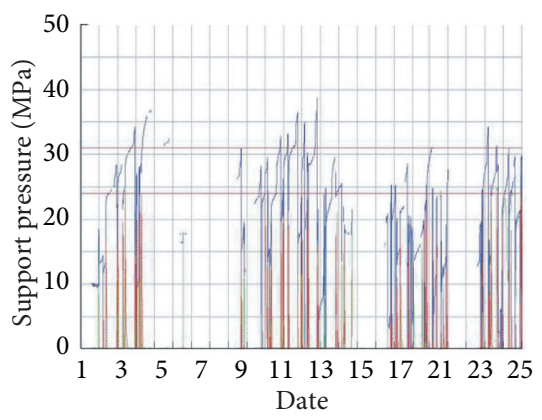

(f)

FIGURE 10: Variation curve of typical support pressure monitored in June 2014 [24]. (a) Support 5\#. (b) Support 15\#. (c) Support 25\#. (d) Support 55\#. (e) Support 75\#. (f) Support 115\#.

TABLE 2: Support pressure of panel 1061 [24].

\begin{tabular}{|c|c|c|c|c|c|c|c|c|c|c|c|c|c|}
\hline Suppo & no. & $5 \#$ & $15 \#$ & $25 \#$ & $35 \#$ & 45\# & $55 \#$ & $65 \#$ & 75\# & $85 \#$ & 95\# & $105 \#$ & $115 \#$ \\
\hline \multirow[t]{2}{*}{ Daily average pressure $(\mathrm{MPa})$} & & 24.2 & 22.4 & 20.2 & 21.9 & 21.5 & 21.1 & 28.7 & 20.8 & 13.7 & 15.2 & 18.8 & 21.6 \\
\hline & & 6 & 29.8 & 28 & 19.4 & 22.5 & 29.7 & 28.5 & 27.3 & 8.6 & 18.5 & 18.9 & 19.9 \\
\hline \multirow[t]{2}{*}{ Support pressure during weighting } & $\mathrm{Ma}$ & 43.2 & 47.4 & 41.1 & 39.7 & 38.5 & 42.7 & 48.4 & 37.1 & 25.8 & 39.2 & 37.8 & 35 \\
\hline & Dynamic pressure coefficient & 1.79 & 2.12 & 2.03 & 1.81 & 1.79 & 2.02 & 1.69 & 1.78 & 1.88 & 2.58 & 2.01 & 1.62 \\
\hline
\end{tabular}

rock bursts, water inrush from bed separation, surface subsidence, and crack. Hence, compared with the influence of single-layer hard thick strata breaking, the strata behaviors produced by DLHTS breaking and instability are much stronger, and it is easier to induce strong dynamic pressure phenomena.

\section{Conclusions}

In this paper, based on the mechanical and structural characteristics of double-layer hard thick strata and their interaction effect, the studies for breaking instability of DLHTS on strata behaviors and the precursory information characteristics of the disasters are carried out by multiscale and multimethods. We can obtain several conclusions as follows:

(i) The high-position DLHTS have bearing, blocking, and controlling effects. Prior to DLHTS breaking, the horizontal development of stress concentration zone and plastic zone can be controlled, and the overburden movement is gentle, while during the breaking process, the stress drops abruptly, the plastic zone expands longitudinally rapidly, the overburden moves obviously, and the energy release is sharp, which is easy to directly cause the appearance of strong dynamic pressure.

(ii) The MLHTS can interact with and influence each other. The LMR breaking can provide sufficient space for UMR movement, while the UMR breaking can promote the LMR periodic breaking in turn and cause its secondary instability, which is easy to form complex or composite dynamic disasters.

Hence, when DLHTS occurs above the working face, the direct impact caused by DLHTS breaking and movement should be paid more attention to and also the LMR periodic breaking and the secondary instability caused by the UMR breaking. Compared with the influence of single-layer hard thick strata breaking, the strata behaviors produced by 
multilayer hard thick strata breaking and instability are much stronger. Study results can provide a scientific basis for the prevention and control of dynamic disaster with multilayer hard thick strata occurrence and provide important guidance value for promoting the safe and efficient production of coalmines.

\section{Data Availability}

The data used to support the findings of this study are available from the corresponding author upon request.

\section{Conflicts of Interest}

The authors declare no conflicts of interest.

\section{Acknowledgments}

The study was funded by the National Natural Science Foundation of China (no. 51804182), Second Batch of Cooperative Education Projects of Ministry of Education in 2019 (no. 201902153001), Shandong Provincial Natural Science Foundation (no. ZR2019BEE065), Key R\&D plan of Shandong Province (no. 2019SDZY034-1), and Support Plan for Outstanding Youth Innovation Team in Shandong Colleges and Universities (no. 2019KJG007).

\section{References}

[1] P. Wang, L. S. Jiang, P. Q. Zheng, G. P. Qin, and C. Zhang, "Inducing mode analysis of rock burst in fault-affected zone with a hard-thick stratum occurrence," Environmental Earth Sciences, vol. 78, p. 467, 2019.

[2] P. Wang, L. S. Jiang, J. Q. Jiang, P. Q. Zheng, and W. Li, "Strata behaviors and rock-burst-inducing mechanism under the coupling effect of a hard thick stratum and a normal fault," International Journal of Geomechanics, vol. 18, no. 2, Article ID 4017135, 2018.

[3] J. Ning, J. Wang, L. Jiang, N. Jiang, X. Liu, and J. Jiang, "Fracture analysis of double-layer hard and thick roof and the controlling effect on strata behavior: a case study," Engineering Failure Analysis, vol. 81, pp. 117-134, 2017.

[4] Z. Li, H. Zhou, D. W. Hu, and C. Q. Zhang, "Yield criterion for rocklike geomaterials based on strain energy and CMP model," International Journal of Geomechanics, vol. 20, no. 3, Article ID 4020013, 2020.

[5] P. Wang, H. Jia, and P. Zheng, "Sensitivity analysis of bursting liability for different coal-rock combinations based on their inhomogeneous characteristics," Geomatics, Natural Hazards and Risk, vol. 11, no. 1, pp. 149-159, 2020.

[6] Z. Li, H. Liu, Z. Dun, L. Ren, and J. Fang, "Grouting effect on rock fracture using shear and seepage assessment," Construction and Building Materials, vol. 242, Article ID 118131, 2020.

[7] B. Xu, J. Q. Jiang, J. Dai, and P. Q. Zheng, "Mechanical derivation and experimental simulation of breaking angle of key strata in overlying strata," Journal of China Coal Society, vol. 43, no. 3, pp. 599-606, 2018.

[8] J.-Q. Jiang and B. Xu, "Study on the development laws of bedseparation under the hard-thick magmatic rock and its fracture disaster-causing mechanism," Geotechnical and Geological Engineering, vol. 36, no. 3, pp. 1525-1543, 2018.
[9] Y. Wang, M. He, and J. Yang, "Case study on pressure-relief mining technology without advance tunneling and coal pillars in longwall mining," Tunnelling and Underground Space Technology, vol. 97, Article ID 103236, 2020.

[10] J. Q. Jiang, J. Dai, P. Wang, and L. L. Zhang, "Overlying hard and thick strata breaking movement and broken-roof control," Rock and Soil Mechanics, vol. 35, no. S1, pp. 264-270, 2014.

[11] J. Q. Jiang, P. Wang, Q. L. Wu, and P. P. Zhang, "Evolutionary characteristics of fracture laws of high-position hard thick strata with elastic foundation boundary," Journal of China University of Mining \& Technology, vol. 45, no. 3, pp. 490-499, 2016.

[12] E. Y. Wang, J. J. Feng, X. G. Kong, X. F. Liu, and R. X. Shen, “A hard roof fracture source model and its far-field seismic impact by stress wave," Journal of Mining \& Safety Engineering, vol. 35, no. 4, pp. 787-794, 2018.

[13] C. Sun, D. X. Chen, Y. H. Cheng, and J. X. Lu, "Study on collapse rule and control of hard roofs in steeply inclined coal seams," Chinese Journal of Rock Mechanics and Engineering, vol. 38, no. 8, pp. 1647-1658, 2019.

[14] Q. T. Hu, C. L. Tian, Y. L. Tan, H. T. Sun, L. C. Dai, and J. Cao, "Study of the hard roof mechanical properties in the process of repeated coal mining," Journal of China University of Mining \& Technology, vol. 47, no. 1, pp. 67-72, 2018.

[15] J. Q. Jiang, P. Wang, Q. L. Wu, and P. P. Zhang, "Evolution laws and prediction of separated stratum space under overlying high-position magmatic rocks," Chinese Journal of Geotechnical Engineering, vol. 37, no. 10, pp. 1769-1779, 2015.

[16] Q. F. Hu, Overburden and Surface Movement Due to High Efficient Mining Extra-thick Coal Seam and Prediction Method, China University of Mining \& Technology, Beijing, China, 2011.

[17] H. Liu, J. Dai, J. Q. Jiang, P. Wang, and J. Q. Yang, “Analysis of overburden structure and pressure-relief effect of hard roof blasting and cutting," Advances in Civil Engineering, vol. 2019, Article ID 1354652, 14 pages, 2019.

[18] H. Liu, P. Wang, Y. Liu, J. Dai, and J. Yang, “A new theoretical method for calculating front abutment stress during coal mining," Energy Science \& Engineering, vol. 8, no. 3, pp. 836-848, 2019.

[19] P. Wang, J. Jiang, P. Zhang, and Q. Wu, "Breaking process and mining stress evolution characteristics of a high-position hard and thick stratum," International Journal of Mining Science and Technology, vol. 26, no. 4, pp. 563-569, 2016.

[20] Y. L. Tan, M. Zhang, Q. Xu, W. Y. Guo, F. H. Yu, and S. T. Gu, "Study on occurrence mechanism and monitoring and early warning of rock burst caused by hard roof," Coal Science and Technology, vol. 47, no. 1, pp. 166-172, 2019.

[21] B. J. Huo, X. D. Jing, B. Yu, and J. Han, "A classification forecasting method for the weighting intensity of stopes of thick coal seams with hard roofs," Chinese Journal of Rock Mechanics and Engineering, vol. 38, no. 9, pp. 1828-1835, 2019.

[22] P. P. Zhang, L. S. Jiang, X. F. Liu, Z. L. Zhang, and X. Liu, "Mining-induced overlying strata structure evolution characteristics and disaster-triggering under high level hard thick strata," Journal of Mining \& Safety Engineering, vol. 34, no. 5, pp. 85-860, 2017.

[23] S. J. Bi and X. Liu, "Feature analysis of microseismic activity and mine pressure under thick hard igneous rock," Shandong Coal Science and Technology, vol. 9, pp. 177-181, 2016. 
[24] Q. L. Wu and Q. S. Wu, "Study on migration law of overlying strata under high hard and thick rock," Metal Mine, vol. 6, pp. 57-60, 2018.

[25] B. Xu, Research on the Movement Characteristics of Superthick Overlying Magmatic and Rock Burst Harzard, Shandong University of Science and Technology, Qingdao, China, 2014.

[26] J. Q. Jiang, P. P. Zhang, G. P. Qin, and B. Xu, "Analysis of destabilized fracture and microseismic activity of high-located main key strata," Rock and Soil Mechanics, vol. 36, no. 12, pp. 3567-3575, 2015.

[27] J. Q. Jiang, P. Wang, L. S. Jiang, P. Q. Zheng, and F. Feng, "Numerical simulation on mining effect influenced by a normal fault and its induced effect on rock burst," Geomechanics and Engineering, vol. 14, no. 4, pp. 337-344, 2018.

[28] P. Wang, L. Jiang, C. Ma, and A. Yuan, "Evolution laws of mining-induced stress in floor strata and its influence on the stability of a floor roadway affected by overhead mining," Earth Sciences Research Journal, vol. 24, no. 1, pp. 45-54, 2020.

[29] H. Wang, C. Jiang, P. Zheng, W. Zhao, and N. Li, "A combined supporting system based on filled-wall method for semi coal-rock roadways with large deformations," Tunnelling and Underground Space Technology, vol. 99, Article ID 103382, 2020.

[30] W. Han, G. Li, Z. Sun, H. Luan, C. Liu, and X. Wu, "Numerical investigation of a foundation pit supported by a composite soil nailing structure," Symmetry, vol. 12, no. 2, p. 252, 2020.

[31] P. Wang, L. S. Jiang, X. Y. Li, G. P. Qin, and E. Y. Wang, "Physical simulation of mining effect caused by a fault tectonic," Arabian Journal of Geosciences, vol. 11, no. 23, p. 741, 2018.

[32] L. S. Jiang, P. Wang, P. Q. Zheng, H. J. Luan, and C. Zhang, "Influence of different advancing directions on mining effect caused by a fault," Advances in Civil Engineering, vol. 2019, Article ID 7306850, 10 pages, 2019.

[33] W. Li, J. W. Bai, K. X. Li, and S. J. Zhang, "Experimental analysis of deformation mechanics and stability of a shallowburied large-span hard rock metro station," Advances in Civil Engineering, vol. 2020, Article ID 4031306, 11 pages, 2020.

[34] P. Wang, L. S. Jiang, and P. Q. Zheng, "Application of equivalent materials to modeling fractures in the vicinity of a normal fault in the area of mining exploitation influence," Acta Geodynamica et Geomaterialia, vol. 14, no. 4, pp. 475485, 2017. 